\title{
BIENESTAR SUBJETIVO Y SUS REPRESENTACIONES SOCIALES EN LA VEJEZ
}

\section{SUBJECTIVE WELL-BEING AND ITS SOCIAL REPRESENTATIONS IN OLD AGE}

Fecha recepción: agosto de 2019 / fecha aceptación: noviembre de 2019

\section{Enrique Hernández Guerson ${ }^{1}$ y Sandra Areli Saldaña Ibarra}

Cómo citar este artículo:

Hernández, E. y Saldaña, S. (2019). Bienestar subjetivo y sus representaciones sociales en la vejez. Revista Pensamiento y Acción Interdisciplinaria, 5(2), 102-117. DOI: http://doi.org/10.29035/pai.5.2.102

\begin{abstract}
Resumen
Investigación que recuperó de personas adultas mayores representaciones sociales de bienestar subjetivo sobre el envejecimiento y la vejez, que contribuye a la comprensión de estos dos procesos, desde una óptica positiva de la salud. La indagación se realizó en el marco de las heterogeneidades del envejecimiento, explicado en diferentes documentos de organismos internacionales, nacionales y de derechos humanos respecto de las personas adultas mayores. Estudio cualitativo de corte interpretativo con dos niveles de profundidad de análisis, descriptivo y analítico. El marco teórico de las representaciones sociales sirve de apoyo, para que recursos técnicos para la investigación, como lo son los testimonios y con recursos de triangulación metodológica, utilizando para tal fin la escala de satisfacción global con la vida, identificó la objetivación de las representaciones sociales del bienestar subjetivo, analizando los textos producidos con estrategias de análisis de contenido, en función de sexo, institucionalización o no, actividad actual remunerativa formal-informal o sin actividad remunerativa. El propósito de comprender los aspectos cualitativos generadores de satisfacción o no, recuperadas de la subjetividad expresada en los discursos de los participantes, para reforzar dichas condiciones de bienestar en las intervenciones de promoción de la salud y psicoeducativas que se implementen para el envejecimiento y vejez.

El artículo contiene el resultado de analizar testimonios de personas mayores, destacando el papel de las redes sociales y una serie de hábitos de vida en el bienestar subjetivo.
\end{abstract}

Palabras claves: Bienestar subjetivo, envejecimiento, objetivación, representaciones sociales, vejez.

\footnotetext{
1. Investigador, mexicano. Licenciada en Psicología, Especialista en Salud Pública, Maestro en Educación y Doctorante en Ciencias Sociales. Instituto de Salud Pública de la Universidad Veracruzana, Xalapa, Veracruz, México. Correo electrónico: enhernandez@uv.mx
}

2 Académica, mexicana. Licenciada en Pedagogía y Maestra en Educación Superior. Instituto de Salud Pública de la Universidad Veracruzana, Xalapa, Veracruz, México. Correo electrónico: ssaldana@uv.mx 


\begin{abstract}
This paper aimed to find out social representations regarding subjective wellbeing on aging and old age, which contributes to understanding these two processes from a positive view of health, from adults older.

Research was carried out in the framework of aging heterogeneities, which is specified in different documents on international, national and human rights organizations with respect to older adults.

An interpretative study with two depth levels of analysis, that is, descriptive and analytical, was conducted. The theoretical framework for social representations provides support, so that technical resources for research, such as testimonies and resources of methodological triangulation can be used. For this purpose, the Satisfaction with Life scale was used. This scale identified the objectivation of social representations regarding subjective wellbeing by analyzing the texts produced with content analysis strategies depending on age group, sex, institutionalization or not, current formalinformal paid or unpaid activity.

In order to understand the qualitative aspects that trigger satisfaction or not, taken from the subjectivity expressed in the discourses of the participants, to reinforce said welfare conditions in the health promotion and psychoeducational interventions that are implemented for aging and old age.

This paper includes the results of analyzing testimonies of elderly people, where the role of social networks and a series of life habits in subjective wellbeing is highlighted.
\end{abstract}

Keywords: Subjective well-being, aging, objectification, representations social, old age

\title{
Introducción
}

Existen múltiples miradas sobre el envejecimiento y la vejez, la biológica, económica, antropológica, sociológica, psicológica, entre otras, estas se focalizan en su objeto de estudio y privilegian sus elementos que estudian en función de los diversos intereses teóricos, empíricos y en los ámbitos de desempeño, pero coinciden en que todas tratan de explicar y comprender y basándose en estos procesos hacen un llamado a la acción respecto de este tema. De tal manera que cada vez se actualiza e innova el conocimiento y el llamado a prestar atención en términos de políticas públicas, estrategias y líneas de acción que responda a estos procesos. En los últimos años, investigadores se han ocupado de un fenómeno psicosocial vinculado a la visión negativa de la vejez, denominada por Butler viejísimo (citado por Mendoza, Martínez-Maldonado y Vargas, 2018), caracterizado por actitudes y acciones discriminatorias de rechazo, tendencia a la marginación, temor, desagrado y agresión a las personas envejecidas, en el ámbito cotidiano los prejuicios y estereotipos se relacionan y se valora a priori a los ancianos; las más de la veces constituyen elementos de gerontofobia, Abric (citado por Rodríguez, 2011 , p. 6) ha tratado de explicar cómo se ha construido desde las representaciones sociales este fenómeno de viejismo, expresaba que para ciertos objetos o fenómenos sociales existe una zona muda de representación social. La zona muda 
está compuesta de elementos que no son verbalizados, aquello que se piensa sobre el tema, pero no se dice, está ligado a ideas estereotipadas o prejuicios, son aquellos supuestos que están ligados al saber de la gente, pero que no se basan en conocimientos totalmente reales. Ante este fenómeno, es necesario replantearse el sentido de la palabra vejez, comprenderlo a partir de la constatación de viejos vitales: hacen ejercicio, se divierten o trabajan con la computadora o el celular, bailan, se alimentan mejor, talentosos, enteros "como robles" (Reyes y Villasana, 2017, p. 62) o “mujeronas" (Kelly y Ibargüengoitia, 2014, p. 11).

El Informe Mundial sobre el Envejecimiento y la Salud, de la Organización Mundial de la Salud (OMS), reafirma con datos recientes sobre el proceso de envejecimiento, lo anotado en líneas anteriores, dice que muchas percepciones y suposiciones usuales acerca de las personas mayores se basan en estereotipos obsoletos. Datos empíricos-señala el informe- demuestran que la pérdida de capacidad, generalmente asociada con el envejecimiento, solo se relaciona vagamente con la edad cronológica de una persona. No existe una persona mayor típica, la diversidad resultante en las capacidades y las necesidades de salud de las personas mayores no es aleatoria, sino que se basa en hechos ocurridos a lo largo del curso de la vida que a menudo pueden modificarse, lo que pone de manifiesto la importancia de este enfoque. Aunque se reconoce que la mayoría de las personas mayores experimentarán múltiples problemas de salud, la edad avanzada no implica dependencia. Considera el informe que con políticas y servicios adecuados, el envejecimiento de la población puede verse como una buena y nueva oportunidad, tanto para las personas como para las sociedades. Menciona que hoy en día, por primera vez en la historia, la mayoría de las personas puede aspirar a vivir más allá de los 60 años y por tanto, para realizar políticas públicas para el envejecimiento y vejez, se debe considerar la diversidad de la vejez, el impacto de la inequidad, los estereotipos anticuados, las nuevas expectativas, los derechos humanos de las personas mayores y aprovechar estrategias para tener un nivel máximo de salud (OMS, 2015). Como dice Patricia Kelly e Ibargüengoitia (2014), pues más allá de la definición de proceso que se da en la biología y cronología, tiene que abrirse un modo de entenderlo, a partir de la constatación de viejos vitales, talentosos y enteros.

La 69a Asamblea Mundial de la Salud, convocada por la OMS (2016), hace énfasis en la necesaria acción multisectorial para un envejecimiento saludable, visualizando que la Agenda 2030 para el Desarrollo Sostenible, son una plataforma para abordar los problemas y las oportunidades del envejecimiento de la población y sus consecuencias de forma integral, con la promesa de que nadie quedará atrás. Paralelo a estos argumentos, otras disciplinas científicas distintas a la salud, por ejemplo: las ciencias sociales, la psicología, la demografía, la gerontología, la biología y otras, han contribuido a incrementar el conocimiento del envejecimiento y la vejez, dando lugar al desarrollo de estrategias para que se alcance en la vejez los máximos de salud posibles; a mediados del Siglo XX se hace énfasis en la mirada subjetiva, estudios longitudinales en las personas mayores, 
contribuyen ampliar el marco comprensivo para una vida larga, satisfactoria y agradable. Muchos de estos estudios han tenido efecto en la sociedad, la académica y en políticas públicas, por los aportes a la comprensión del envejecimiento, por ejemplo, el conocido Estudio de Baltimore, que analizó el modo en que evoluciona la salud de las personas, una de sus conclusiones, que contribuyó a llamar la atención sobre ciertos prejuicios del envejecimiento y vejez, fue de que estos procesos no son lo mismo; si bien el riesgo de padecer patologías aumenta con la edad, hay personas que envejecen con buena salud. El estudio demuestra, por tanto, que envejecer de forma saludable no constituye una utopía, sino un objetivo al que se puede aspirar (Inzitari, 2010). Schirrmacher, (2004) escribía que ser viejo no debe equiparase a ser débil o estar cansado. En su libro, El complot de Matusalén, recupera resultados de un estudio longitudinal sobre el envejecimiento, que inició en el año 1975 y cuyos resultados se dieron a conocer en 2002 por Levy, Salde, Kunkel y Stanislav. Los investigadores aportaron evidencias de participantes que consideraban el envejecimiento como una fase más de sus vidas y aquellos que tenían una imagen positiva de los ancianos, vivían un promedio de siete años y medio más que los que no esperaban nada de la vejez. Esta diferencia persiste-escriben-, incluso tomando en cuenta el status social, económico, el sexo, las relaciones sociales y la salud. Otras investigaciones señalan que el concepto de bienestar alude a condiciones materiales externas y aquellas, que apuntan al disfrute de estados internos de la persona considerados como valiosos y que se ve reflejado en el contexto personal, familiar y social, con implicaciones en términos de satisfacción social, psíquica y espiritual, es decir, bienestar subjetivo (Valdés, 1991). Carmona (2009), reporta una relación predictiva de las interacciones sociales, la escolaridad, la autonomía y la salud con el bienestar personal de adultos mayores. El estrato socioeconómico, el género, el estado civil y la edad no contribuyeron significativamente al bienestar personal del adulto mayor. Sarabia (2009), define el bienestar subjetivo como el grado de satisfacción que experimentan las personas cuando hacen una valoración o juicio global de sus vidas. Viviola (2007), en su investigación reporta que los dominios referidos a relaciones afectivas, futuro, trabajo y la percepción de auto eficacia explican un porcentaje alto de la variable del bienestar subjetivo.

Las líneas anteriores muestran que es preciso saber más sobre la salud en la edad avanzada y definir concretamente qué se puede hacer para mejorarla, ya que en la salud de las personas mayores, no solo influyen los sistemas de salud y atención a largo plazo, sino también el entorno en el que viven y han vivido toda su vida, lo antes dicho sirve de argumento para indagar ¿Cómo las personas mayores representan socialmente el bienestar, considerando su experiencia de vida? Para dar respuesta a la interrogante, la investigación se enmarca en las representaciones sociales (RS); teoría que trata de la manera cómo las personas se apropian de los conocimientos e información que circulan en la sociedad; cómo en el dialogar de la vida cotidiana se construye un pensamiento social, un conocimiento popular o de sentido común (Castorina y Kaplan, 2008; Moscovoci y 
Hewstone, 1993). "Son conjuntos dinámicos, su característica es la producción de comportamientos y de relaciones con el medio" (Moscovici, 1979, p. 33).

Las RS han mostrado ser útiles como una guía de la acción de las personas en su relación cotidiana con los hechos, siendo así que las personas elaboran actitudes, creencias, emociones, formas de explicación y conductas frente a los hechos a través de un saber social. El campo figurativo, con sus elementos que lo integran, como la construcción selectiva, la esquematización estructurante y la naturalización forjan una visión menos abstracta del objeto representado. Otros procesos que se presentan en las RS son la objetivación y el anclaje. La objetivación transforma el contenido conceptual en imágenes "Es una instancia cognoscitiva de índices y de significantes que una persona recibe, emite y trama en el ciclo de las infracomunicaciones" (Moscovici, 1979, p. 75). El anclaje integra dentro de nuestro sistema de pensamiento información sobre el objeto, lo interpreta, da sentido a ese y a nuevos objetos que aparecen en el campo social e interacciona a partir de este producto. "La objetivación traslada la ciencia al dominio del ser y el anclaje en el del hacer" (Moscovici, 1979, p. 121). Las RS, en la presente investigación, destaca la capacidad de los actores de que expresen cuáles son, en su vejez, las razones de satisfacción o no de su vida. Con el supuesto hipotético que, el sentirse satisfecho con uno mismo, tiende a incrementar la participación social y puede contribuir a la salud de las personas mayores (Libelalesso, 2002; Meléndez, Navarro-Pardo, Oliver, y Tomás, 2009; Puig Llobet, Rodríguez, Farràs Farràs, y Lluch Canut, 2011; Vera, Figueiredo, Sotelo, y Batista de Alburquerque, F. Montaño, 2002), y observando las siguientes consideraciones:

1. Cuando más multifacético es la persona en su vejez, mayores las probabilidades de bienestar y adaptación; 2. Cuando la Persona Adulta Mayor (PAM) ejerce sentido de control, autoeficacia y dominio de la capacidad de auto dirigirse, mayor posibilidad de bienestar subjetivo; 3. Cuanto mayor sea su esquema social: aceptación social y compromiso social de la PAM, mayor su percepción de bienestar y 4. Si la PAM actúa como moderador o amortiguador de los impactos negativos de la vida, mayor bienestar. 


\section{Metodología}

Se recuperan testimonios de PAM en los cuales se identifican y analizan las Representaciones Sociales (RS) generadores de bienestar subjetivo. 1. Tipo de estudio cualitativo, de corte interpretativo (Hernández, 2000); 2. Tipos sociales: personas adultas mayores de 60 años; 3 .Variables discusivas: hombres y mujeres adultas mayores, no institucionalizadas y con actividad remunerativa y no; 4. Diseño: 24 testimonios y 24 documentos de la Escala de Satisfacción Global con la Vida de personas adultas mayores no institucionalizadas. Hombres y mujeres; 5. Categoría: Bienestar subjetivo entendida como la satisfacción que experimentan las personas cuando hacen una valoración o juicio global sobre sus vidas (Ballesteros, 2007). Puede ser distinto a las condiciones de vida objetivas. 6. Subconceptos: Componente afectivo (Sentimientos y emociones); Componente social (relaciones, participación social, género); Actividad remunerativa (prestar servicios públicos o privados y recibir pago económico por esa actividad prestada); Actividad no remunerativa (prestar servicios públicos o privados, pero no recibe pago económico por esa actividad o no prestar servicios). Condición de no institucionalización (no estar incorporado a una institución de cuidados de vida, al menos 15 días previos a la entrevista). Componente cognitivo (satisfacción entre nivel de aspiración y realización) y Componente físico (mantenimiento y funcionalidad de la salud física y mental); 7. Instrumentos de recolección de información: a) Testimonios: (Vasilachis de Gialdino, 2006) en diversas formas testimonios manuscritos (con o sin la presencia del investigador); por correo electrónico; orales (grabados con la presencia del investigador), con tres preguntas tema: ¿Hay cosas de su vida por las que esté satisfecho, a gusto, contento actualmente? ¿Hay cosas de su vida, que si usted pudiera modificar o cambiar, lo haría actualmente? ¿Hay cosas de su vida que hayan contribuido a que esté en las condiciones físicas y mentales en que encuentra? Al finalizar el testimonio se aplicó: b) Escala de satisfacción global con la vida (Libelalesso, 2002). 8. Estrategia de análisis: centrado en el sujeto y su discurso, recuperando hablas que permitan dilucidar las RS de la experiencia global de vida y el bienestar subjetivo (Hernández y Granados, 1998; Mercado y Torres, 2000; Saldaña y Hernández, 2002). 


\section{Resultados y discusión}

Este aporte es parte de una investigación más amplia respecto del bienestar subjetivo que incluye a más tipos sociales, variables discursivas, escenarios y ámbitos. El presente enuncia los datos de la variable discursiva no institucionalizadas con o sin ingresos estables, hombres y mujeres según pertenecientes a grupo de edad de 60 y más años.

Caracterización de las participantes: participaron 24 personas adultas mayores, catorce mujeres y diez hombres, quienes presentaron las siguientes condiciones:

\begin{tabular}{|c|c|c|c|c|}
\hline & \multicolumn{2}{|c|}{ Mujeres } & \multicolumn{2}{|c|}{ Hombres } \\
\hline & $\begin{array}{l}\text { Con ingreso } \\
\text { económico } \\
\text { estable }\end{array}$ & $\begin{array}{l}\text { Sin ingreso } \\
\text { económico } \\
\text { estable }\end{array}$ & $\begin{array}{l}\text { Con ingreso } \\
\text { económico } \\
\text { estable }\end{array}$ & $\begin{array}{l}\text { Sin ingreso } \\
\text { económico } \\
\text { estable: }\end{array}$ \\
\hline Total & 8 & 6 & 6 & 4 \\
\hline $\begin{array}{l}\text { Nivel de } \\
\text { escolaridad: }\end{array}$ & $\begin{array}{l}3 \text { primaria; } \\
1 \text { secundaria; } \\
2 \text { licenciatura; } \\
2 \text { posgrado }\end{array}$ & $\begin{array}{l}3 \text { primaria; } \\
3 \text { secundaria }\end{array}$ & $\begin{array}{l}1 \text { sin escolaridad; } \\
2 \text { secundaria; } \\
3 \text { posgrado. }\end{array}$ & $\begin{array}{l}1 \text { sin escolaridad; } \\
1 \text { primaria; } \\
2 \text { primaria } \\
\text { incompleta; }\end{array}$ \\
\hline $\begin{array}{l}\text { Fuente de } \\
\text { ingreso }\end{array}$ & $\begin{array}{l}2 \text { pequeñas } \\
\text { comerciantes y } \\
6 \text { reciben pensión }\end{array}$ & $\begin{array}{l}1 \text { pide limosna; } \\
5 \text { sin ingresos }\end{array}$ & $\begin{array}{l}3 \text { Pensión; } \\
1 \text { pequeños } \\
\text { comerciante; } \\
2 \text { activo }\end{array}$ & $\begin{array}{l}1 \text { cuida coches; } \\
1 \text { cerillos; } \\
1 \text { pide limosna; } \\
1 \text { bolero. }\end{array}$ \\
\hline $\begin{array}{l}\text { Condición } \\
\text { civil: }\end{array}$ & $\begin{array}{l}3 \text { separadas; } \\
3 \text { viudas; } \\
1 \text { soltera; } \\
1 \text { divorciada }\end{array}$ & $\begin{array}{l}1 \text { separada; } \\
4 \text { viudas; } \\
1 \text { soltera }\end{array}$ & $\begin{array}{l}2 \text { casados } \\
1 \text { separado } \\
1 \text { viudo; } \\
2 \text { solteros }\end{array}$ & $\begin{array}{l}2 \text { casados; } \\
1 \text { unión libre } \\
1 \text { viudo; }\end{array}$ \\
\hline
\end{tabular}

La obtención de testimonios: de los 24 testimonios (con fuente de ingreso estable o sin ella), 19 fueron cara a cara y grabados; uno por correo electrónico y cuatro escritos. Los espacios de obtención fueron en casa, consultorios, centros educativos o donde se encontraban los sujetos haciendo sus actividades, por ejemplo, fuera de un banco y en los pasillos de un andador comercial donde pedían limosna, en un área de mercado donde limpiaban zapatos o en las afueras de la 
plaza comercial y recreativa, en estacionamiento comercial donde se ocupaban cuidando coches, empacando productos o en la calle y avenidas de alta afluencia peatonal y zona laboral vendiendo productos alimenticios o dulces.

Acercamiento a las variables discursivas: el acercamiento dependió del escenario en donde se recogieron los testimonios; la vestimenta y el equipo que se utilizó fueron en el sentido de tratar acorde con ese escenario. Una de las variables discursivas no aceptó la grabación y otra rechazó participar, aludiendo que la empresa en que desempeñaban sus actividades le tenía prohibido hablar con personas en su trabajo o bien recibían represalias si decía algo en contra de la empresa pues aducían que les daban oportunidad de realizar sus funciones de cerillo (Es de conocimiento popular decir que los cerillos, es una denominación hacía personas, mujeres u hombres, menores de edad o mayores que son identificados en cadenas comerciales; se ocupan de embolsar productos que los clientes compran) y sentían que corrían riesgo de que ya no les dieran oportunidad de trabajar si daban la entrevista.

Estilos de moderación en la entrevista: fueron varias las tácticas utilizadas, dada la variabilidad de personalidades y tipos de habla; se puede mencionar tácticas: de silencio, de animación y de reafirmar. La post-entrevista en particular fue de gran utilidad, como su nombre lo indica es una prolongación del encuentro formal, a micrófono cerrado; fue una oportunidad para obtener información que el entrevistado se había reservado durante el evento.

Objetivación y anclaje: son varios los términos y las imágenes con las que objetivan el bienestar subjetivo y les facilita su relación con los que interactúan: el tener un hogar, una familia, sentirse querida y satisfecha por lo realizado en su trayectoria de vida; el poseer buenas condiciones de salud físicas, cognitivas (mentales), sociales y con ello la imagen de autosuficiencia, de alcanzar objetivos, de sonreír y gozar de tranquilidad.

En todos los testimonios aparecen el anclaje en relación con los otros, por ejemplo, con las comunidades o grupos a los que dicen pertenecer, sean de tipo primario, tal como amistades, hijos, nietos o grupos secundarios como de trabajo, manifestando bienestar subjetivo por hacer un bien o por aportar con lo que realiza a la satisfacción de los demás, sea afectiva, material o social la aportación. El sentido de pertenencia e identidad a una comunidad o grupos sociales es uno de los elementos identificados como anclaje; les brinda bienestar subjetivo el dar, ser y poder acompañar a otros. También el sentirse amada, acompañada y disponer de tiempo para reflexionar sola o acompañada, son otros elementos del anclaje.

Enseguida se presentan segmentos que reflejan lo antes dicho, y se enuncian con relación a cuatro supuestos hipotéticos propuestos que orientaron el encuentro de los hallazgos en el análisis de los discursos, que describe que el bienestar subjetivo que experimentan las personas cuando hacen una valoración o juicio global sobre sus vidas, estaba en consideración de las siguientes: 


\section{Cuando más multifacético es la persona en su vejez, mayor posibilidad de bienestar}

Aparece en todos los entrevistados que manifestaron que algo que les hacía sentir a gusto, satisfecho o contento actualmente, fue tener diferentes roles, por ejemplo, el de papá o abuelo, seguir trabajando, hacer actividades adicionales al trabajo principal; tener pareja, entre otros.

Como nos dijo José:

En general he llevado una vida sana, no he fumado nunca, no he tomado; casi siempre he hecho algo de ejercicio. En la actualidad camino casi tres kilómetros diarios con paso rápido. De vez en cuando algo de chi kum o yoga. Me gusta mucho leer, hacer crucigramas y estar activa siempre. Estoy muy interesado en la filosofía de Shiva ismo y trato de practicar la meditación, lo cual me ayuda a superar muchos de los problemas que venía arrastrando desde la infancia y me ha ayudado a comprender mejor a mis semejantes, así como a apreciar el momento y valorar cada maravilla que nos regala la vida.

Los testimonios expresaron que el tener pareja (casados o en unión libre) era los que les hacía sentir con bienestar, por ejemplo Víctor, no tiene trabajo, por tanto no goza de ingreso económico estable, para tenerlo, limpia zapatos en vía pública, y todas otras cuestiones de vida le crean actualmente una situación vulnerable: paga renta, su salud física la considera deteriorada, a raíz de accidente ferroviario, una máquina y sus cabus le pasaron encima de su pierna cuando era más joven; a raíz de ese incidente le falta en su cuerpo un tobillo y pie; tiene problemas en la columna, para desplazarse usa muletas; expresa tener dificultades reumatoides que le ha provocado que sus extremidades superiores se encuentren alteradas, entre otras más de tipo físico y social. Al preguntarle el puntaje que se aplicaba en la Escala de Satisfacción en la Vida y otorgarse un puntaje arriba de 6 puntos, intrigado se le preguntó en que se había basado para ese puntaje y dijo:

"Tengo como compañera una pareja joven y un hijo, por eso me pongo esa calificación"

O bien, el testimonio de Manuel, profesional con trabajo e ingreso estable, desarrollando múltiples roles satisfecho de cada uno, en el que reconoce que su pasado tuvo diversas relaciones afectivas, procreado con esas parejas hijos, nos decía:

"Reciente hace unos dos años he iniciado una relación afectiva que me ha ido bien, veo a mis hijas sin mayor problema" 
O Javier que decía, de que a pesar de ver a su pareja solo los fines de semana (ella no era del mismo lugar de vecindad que él), pues se ve en la necesidad de estar todo el día trabajando en una ciudad diferente a la de su pareja; relata que recién le habían intervenido quirúrgicamente, no tener trabajo e ingresos estables y de reunir otras situaciones de vulnerabilidad, decía:

"Espero cada fin de semana para ir a ver a mi esposa e hijo, no importa que haga hasta cuatro horas de viaje para hacerlo"

Por medio de comparar las hablas de los testimonios que decían que tener pareja fue lo que les daba bienestar en estos momentos de su vida, se puede deducir que la elección de vivir acompañado es motivo de bienestar subjetivo, no importando la cuestión de satisfactores objetivos sociales, ni económicos, ni ordenamientos morales de una sociedad convencional.

\section{Cuando ejerce sentido de control, autoeficacia y dominio de la capacidad de auto dirigirse, mayor posibilidad de bienestar subjetivo}

Efectivamente, el sentir que se tiene control de las cosas y sentirse competente para algo, les hace sentir bienestar subjetivo, por ejemplo Carolina, mujer de 64 años, viuda desde hace 15; madre de dos hijas (una estudiante universitaria y otra profesionista). Su bienestar radica en que a pesar de ser viuda y vivir parte de su vida con dos hijas bajo su responsabilidad, expresaba su satisfacción de que a partir de su negocio informal de venta de alimentos, había logrado que sus hijas estudiaran una carrera:

"Miré yo enviudé hace ya varios años, me quedé sin saber qué hacer con dos hijas, un buen día estaba desesperada y que hago un poco de gordas y enchiladas para vender, que salgo a la calle, exactamente aquí donde todavía estoy. Me fue bien y cada vez me fue mejor que pude darles carrera universitaria a mis dos hijas"

O Isaías, que con su venta de dulces había logrado hacer un patrimonio en vivienda y compartirlo con sus hijos (en un terreno de 300 metros logró construir una casa para él y dos más para sus hijos); atribuir su bienestar subjetivo a un estado físico ya que en su vida pasada estuvo alejado de hábitos nocivos de vida, tal como no fumar o no beber alcohol y a tener una alimentación saludable y un estilo de vida alejado de personas negativas, preservando su salud mental. 


\begin{abstract}
"Miré mi vida laboral siempre fue satisfactoria, tuve buenas relaciones con todas las personas y pude hacer la casita para mis hijos, pero que creo que fue benéfico para mi vida, cortar la vuelta a las personas negativas"
\end{abstract}

Carrito, de 87 años de edad, sin escolaridad, cuya representación de bienestar subjetivo es que a su edad tiene trabajo que le permite tener ingresos económicos para él, sus hijas y una nieta que viven con él; atribuye su condición física y mental a la decisión de seguir principios alimenticios:

\begin{abstract}
"Todas las mañanas me tomó dos medios vasos de agua, enseguida una cucharadita de miel y enseguida me baño con agua fría. Es mi rutina que realizo desde hace muchos años y hace una pregunta: ¿cree qué es esto lo que ha ayudado a estar en las condiciones actuales?"
\end{abstract}

Su frustración en este momento de su vida es una pena moral con su difunto padre por haberse cambiado el nombre y el hecho de no tener estudios.

\title{
Cuanto mayor seasu esquema deaceptaciónsocial ycompromiso social.
}

Teresa nos dijo que:

\begin{abstract}
"Estoy a gusto, satisfecha y contenta porestarviva aparentemente sana, contar con una familia y tener hogar para compartir todos los días, amar y poder ser útil a los que viven conmigo y a mis familiares, ser amada por todos y cada uno de ellos en todo momento, por ocupar un lugar en mi comunidad. Porque cuento con amigos y amigas leales y sinceros. Por haber alcanzado mis objetivos como ser humano, como profesional y como mujer, (a pesar que no tuve hijos); por poder seguir apoyando de acuerdo a mis posibilidades a mis compañeros jubilados y a las personas que me solicitan un consejo u orientación o un servicio. Por ser autosuficiente física, mental y económicamente, lo cual me permite disfrutar de la naturaleza, conmoverme con un amanecer o atardecer y valorar esos momentos que Dios nos brinda gratis todos los días".
\end{abstract}


O las expresiones de Hilda, al referir de su satisfacción por su vida:

"Por tener una vida tranquila, una vejez sin privaciones, estar satisfecha física, mental y sentimentalmente con lo que tengo, pues aun cuando no gozo de completa salud, me siento apta para realizar muchas cosas, con ciertas limitaciones por mi edad, pero no dependo de los demás, tengo libertad para realizar la mayor parte de mis actividades"

\section{Si en su vida actúo como moderador o amortiguador de los impactos negativos de la vida.}

Sergio nos manifestó que tuvo una infancia humilde en términos sociales y económicos. Su padre tenía un empleo humilde consistente en empacar refrescos y él solía ayudarlo. Tuvo la fortuna (palabras de Sergio), de tener personas que lo animaron a estudiar más allá de la educación básica y para apoyarlo a salir de su lugar de origen para estudiar la universidad. Lo logró, hizo estudios universitarios, tanto de licenciatura como de especialidad, logró reconocimiento de su ejercicio profesional; tuvo frutos en el aspecto económico y social. En lo familiar enviudo hace 15 años, quedándose a vivir solo, expresa que rodeado del cariño de sus hijas y amigos; a la fecha de este reporte vive con problemas de salud visual, músculo esquelético en cuestiones de movilidad y padecimientos cognitivos en cuestión de memoria selectiva de corto y largo plazo. Este curso de vida de situaciones adversas en todos los aspectos, su fuente de bienestar subjetivo es que todas sus hijas son reconocidas en su campo profesional y todas con estudio de doctorado; en palabras de él, dos frases resumen su vida:

"Como te ves, me vi, como me vez quien sabe si llegues a verte"

En la cual expresa su bienestar subjetivo por la edad que tiene y estar en las condiciones físicas en las que se encuentra. La otra frase tiene sentido de vida para Sergio, ya que refleja lo que tuvo que pasar en su desarrollo profesional y laboral, frase que fue compartida por un antiguo jefe y que justificaba ciertos comportamientos que tuvo hacia otras personas y que Sergio pudo observar, y al preguntarle la razón de ese comportamiento, su ex jefe le dijo:

\section{"Cuando eres buey, aguanta; cuando eres martillo, pega"}

Imagen que Sergio adoptó de orientación para el comportamiento en las diferentes esferas de su vida, reconociendo ahora, que no fue lo mejor que pudo tener como referencia para todos los roles que tuvo, por ejemplo el de la familia. Sin embargo en otras áreas le facilitó su desarrollo. 
A modo de discusión, todos los testimonios que expresaron sentirse bien, a gusto, satisfecho con su vida, fueron RS con referencia a ser autosuficiente física, mental y socialmente; estar acompañado, vivir con y hacia los demás, aunque no se perciba o esté necesariamente sano, pero siempre la RS de bienestar subjetivo es estar o vivir acompañado. La participación social es la RS que las personas adultas mayores de esté estudio les hace sentir bienestar subjetivo, por ejemplo el ser productivas, lo anterior sin distingos de edad y sexo según los grupos estudiados. Contar con pareja, amigos, relaciones sociales, salud y trabajo son también RS de bienestar subjetivo, seguramente la relación interpersonal con la familia, los amigos, los vecinos y otros satisface la necesidad humana de contacto social, manifestada a través de emociones. Ocuparse en su vida por tener en relaciones sociales sólidas, compartir con alguien la vida es importante para el bienestar subjetivo.

Los hallazgos permiten resaltar cuatro aspectos relativamente estables: el uno es que la concepción psicosocial, la interacción y sentido de pertenencia con diversos grupos primarios o secundarios, es la RS que configura el bienestar subjetivo; el segundo es que la construcción de las RS están acompañadas de actividades individuales que anteceden y acompañan esa construcción; el tercer aspecto, es que a pesar de los condicionamientos objetivos de bienestar en la vida, el aspecto mental resulta ser fundamental para el bienestar subjetivo, algo similar reconoce Aarón Antonovsky con el concepto de "Sentido de Coherencia" (SOC) (Hernan, Morgan, y Mena, 2010, p. 32) o Mabel Munist con el de resiliencia (Munist et al., 1998, p. 8); el cuarto aspecto fue, que en el habla de los participantes se hizo referencia a aspectos de filosofía práctica como modelo del curso de vida, expresado este modelo filosófico de vida de forma rudimentaria, mediana o suficientemente elaborado, por ejemplo, que se debe actuar siempre de todo corazón, o bien, que lo que se requiere hacer está en nuestro interior, o que el valor de las cosas se demuestra en la práctica por su utilidad, o que las cosas que se logran son con sufrimiento. Por el contrario, estar o vivir solo, no ser autosuficiente física, mental o socialmente; no haber cumplido aspiraciones cuando joven, diferencias entre expectativas y realización, por ejemplo, no haber estudiado, no haber tenido hábitos de vida saludables o comportamientos amorales son objetivación y anclaje de no bienestar subjetivo.

Los resultados del estudio abonan a reconocer que el bienestar subjetivo es parte de un patrón de envejecimiento más saludable, sin embargo, se genera una nueva interrogante ¿Es está conceptualización filosófica identificada en el curso de la vida la que promueve que algunas personas mayores mantengan una vida con bienestar subjetivo, a veces excepcional, a pesar de haber tenido experiencias adversas y haber estado expuesto a factores de riesgo? 


\section{Referencias bibliográficas}

Asamblea Mundial de la Salud, 69. (2016). Acción multisectorial para un envejecimiento saludable basado en el ciclo de vida: proyecto de estrategia y plan de acción mundiales sobre el envejecimiento y la salud: Informe de la Secretaría. Organización Mundial de la Salud. Recuperado de https://apps. who.int/iris/handle/10665/253025

Ballesteros, S. (2007). Envejecimiento saludable: aspectos biológicos, psicológicos y sociales. Madrid: Universitas.

Carmona Valdés, S. (2009). El bienestar personal en el envejecimiento. Iberoforum. Revista de Ciencias Sociales de la Universidad Iberoamericana, IV(7), 48-65.

Castorina, J. y Kaplan, C. (2008). Las representaciones sociales: problemas teóricos y desafíos educativos. En Castorina J. (Comp.). Representaciones sociales: problemas teóricos y conocimientos infantiles, (pp. 9-28). Argentina: Gedisa.

Hernan, M., Morgan, A., y Mena, A. (2010). Formación en salutogénesis y activos para salud. Andalucia: Consejería de Salud y Bienestar Social.

Hernández, E. (2000). Entre paradigmas y orientaciones. Revista de la Universidad Cristóbal Colón, 1(9), 13-30.

Hernández, E., y Granados, L. (1998). Una aproximación al análisis cualititativo. Enseñanza e Investigación en Psicología, 3(2), 89-101.

Inzitari, M. (2010). Estudios longitudinales sobre envejecimiento: pasado, presente y futuro. Revista Española de Geriatría y Gerontología, 45(2), 103-105.

Kelly, P., y Ibargüengoitia, A. (2014). Mujeres grandes. México: Sincronía encuentros.

Libelalesso, A. (2002). Bienestar subjetivo en la vida adulta y en la vejez. Hacia una psicología positiva en América Latina. Revistas Científicas de América Latina, El Caribe, España y Portugal, 4(1-2), 55-74.

Meléndez, J., Navarro-Pardo, E., Oliver, A., y Tomás, J. (2009). La satisfacción vital en los mayores. Boletín de Psicología, (95), 29-42.

Mendoza, N. V., Martínez-Maldonado, M., y Vargas, G. L. (2018). Viejísimo: prejuicios y estereotipos de la vejez. México: UNAM.

Mercado, F., y Torres, T. (2000). Análisis cualitativo en salud. Teoría, método y práctica. México: Plaza y Valdés. 
Moscovici, S. (1979). El psicoanálisis, su imagen y su público. Buenos Aires: Huemul.

Moscovoci, S., y Hewstone, M. (1993). De la ciencia al sentido común. En Moscovici, S. (Ed.). Psicología Social II. Pensamiento y vida social: psicología social y problemas sociales, (pp. 679-710). Barcelona: Paidós.

Munist, M., Santos, H., Kotliarenco, M., Suárez, E., Infante, F. y Grotberg, E. (1998). Manual de identificación y promoción de la resiliencia en niños y adolescentes. Suecia: OPS.

OMS. (2015). Informe mundial sobre el envejecimiento y la salud. Estados Unidos de América: OMS.

Puig Llobet, M., Rodríguez, N., Farràs Farràs, J., y Lluch Canut, M. (2011). Qualidade de vida, felicidade e satisfação com a vida em anciãos com 75 anos mais, num programa de atenção domiciliária. Revista Lanio-Americana de Enfermagem, 19(3), 15-23.

Reyes, L., y Villasana, S. (2017). Los achaques asociados a la vejez. En Z. Ronzón, F. Vázquez, y V. Munguía (Eds.), Vejez y vulnerabilidad, (pp. 57-91). Ciudad de México: UAEM-Gedisa.

Rodríguez, T. (2011). Discusiones teórico-metodológicas sobre el carácter contextual de las representaciones sociales. Sinéctica, 36, 1-11. Recuperado de http://www.scielo.org.mx/scielo.php?script=sci_arttextypid=S1665109X2011000100004ylng=esytlng=es.

Saldaña, S., y Hernández, E. (2002). Horrores más comunes del análisis cualitativo. Revista de la Universidad Cristóbal Colón, 1(13-14), 13-30.

Sarabia, C. (2009). Envejecimiento exitoso y calidad de vida. Su papel en las teorías del envejecimiento. Gerokomos, 20(4), 172-207.

Schirrmacher, F. (2004). El complot de Matusalén. México: Santillana.

Valdés, M. (1991). Dos aspectos en el concepto de bienestar. Doxa, (9), 69-89.

Vasilachis de Gialdino, I. (2006). Estrategias de investigación cualitativa. Barcelona: Gedisa.

Vera, J. Á., Figueiredo, S., Sotelo, T., Batista de Alburquerque, F. y Montaño, A. (2002). Vejez y satisfacción con la vida en Brasil. Intercontinental de Psicología y Educación, IV(1), 35-65.

Viviola, C. P. (2007). Los factores predictores de bienestar subjetivo en una muestra Colombiana. Revista Latinoamericana de Psicología, 39(2), 311-325. 
Pensamiento y Acción Interdisciplinaria, Volumen 5, número 2, año 2019. ISSN 0719-8078. pp. 102-117

Dirección de correspondencia:

Enrique Hernández

Investigador. Licenciatura en Psicología, Especialista en Salud Pública, Maestro en Educación y Doctorante en Ciencias Sociales. Instituto de Salud Pública de la Universidad Veracruzana, Xalapa, Veracruz, México.

\section{Contacto:}

enhernandez@uv.mx 